\title{
Launching the Resource Repository for Assessment Librarians: From Needs Assessment to Pilot and Beyond
}

\author{
Nancy B. Turner \\ Temple University Libraries, USA \\ Kirsten Kinsley \\ Florida State University, USA \\ Melissa Becher \\ American University Library, USA
}

\section{Introduction and Setting the Stage}

Building and sustaining a digital repository for sharing resources has great potential in support of a growing community of practice for assessment librarians. Starting in 2015, Jessame Ferguson and committees of the Library Leadership and Management Association ${ }^{1}$ hosted discussions and focus groups to gather input on such an initiative. The idea had traction, although early documents suggest there were wide-ranging thoughts about the scope, procedural policies, and technical infrastructure for such an endeavor.

For instance, an early requirements document describes the concept as an "easy-to-use system for organizing and accessing library assessment examples, products and findings. This will allow librarians to share any type of assessment method and resulting findings, including those that are often never published, such as inconclusive or negative results. Through well-organized searching options, it will allow all librarians to find evidence based assessment models to begin their projects and then compare their findings with the results of others." ${ }^{2}$

The LLAMA Executive Board was behind the idea and provided funds for a consultant to explore and make recommendations for a path forward. Martha Kyrillidou served in that role; her report provided us with a potential design. But there were practical realities, including limited budgetary resources, lack of institutional sponsorship, and limited experience with building a repository like the one envisioned. We reached out to the larger librarian community in order to prioritize and perhaps recalibrate the community needs.

\section{Needs Assessment}

The Needs Assessment Survey was conducted in the spring of 2017 and yielded 379 responses. While primarily academic librarians responded (86\%), we also heard from public librarians (7.7\%) and a variety of special librarians.

We asked respondents to "indicate all of the options that describe how you might use a freely available, online Library Assessment Repository." As indicated in the table below, the highest number ( $\mathrm{N}=360)$ would look for instruments, and far fewer would use the space for sharing their own findings $(\mathrm{N}=247)$.

Figure 1: Use for repository

\begin{tabular}{|l|l|l|}
\hline Answer Options & Response Percent & Response Count \\
\hline $\begin{array}{l}\text { Search the repository for examples of instruments or } \\
\text { tools to use }\end{array}$ & $95.5 \%$ & 360 \\
\hline
\end{tabular}




\begin{tabular}{|l|l|l|}
\hline Answer Options & Response Percent & Response Count \\
\hline $\begin{array}{l}\text { Review results, reports or case studies as examples of best } \\
\text { practice }\end{array}$ & $85.1 \%$ & 321 \\
\hline $\begin{array}{l}\text { Deposit instruments (surveys, rubrics, questionnaires) or } \\
\text { tools created by my library or organization to share with } \\
\text { others }\end{array}$ & $82.2 \%$ & 310 \\
\hline Locate peers or colleagues doing similar work as me & $77.2 \%$ & 291 \\
\hline $\begin{array}{l}\text { Review findings from similar studies to compare to my } \\
\text { own findings }\end{array}$ & $76.4 \%$ & 288 \\
\hline Find answers to commonly asked questions & $70.3 \%$ & 265 \\
\hline $\begin{array}{l}\text { Share assessment results or findings from studies done by } \\
\text { my library or organization }\end{array}$ & $65.5 \%$ & 247 \\
\hline $\begin{array}{l}\text { Find other repositories that include assessment-related } \\
\text { resources in my area of interest }\end{array}$ & $59.9 \%$ & 226 \\
\hline Other (please specify) & $3.4 \%$ & 13 \\
\hline
\end{tabular}

Related to this question, we asked how likely respondents would be to use various types of resources. By a large margin, assessment instruments and reviews of assessment tools would be used. Least likely to be used are raw data.

\section{Figure 2: Likely used resource types}

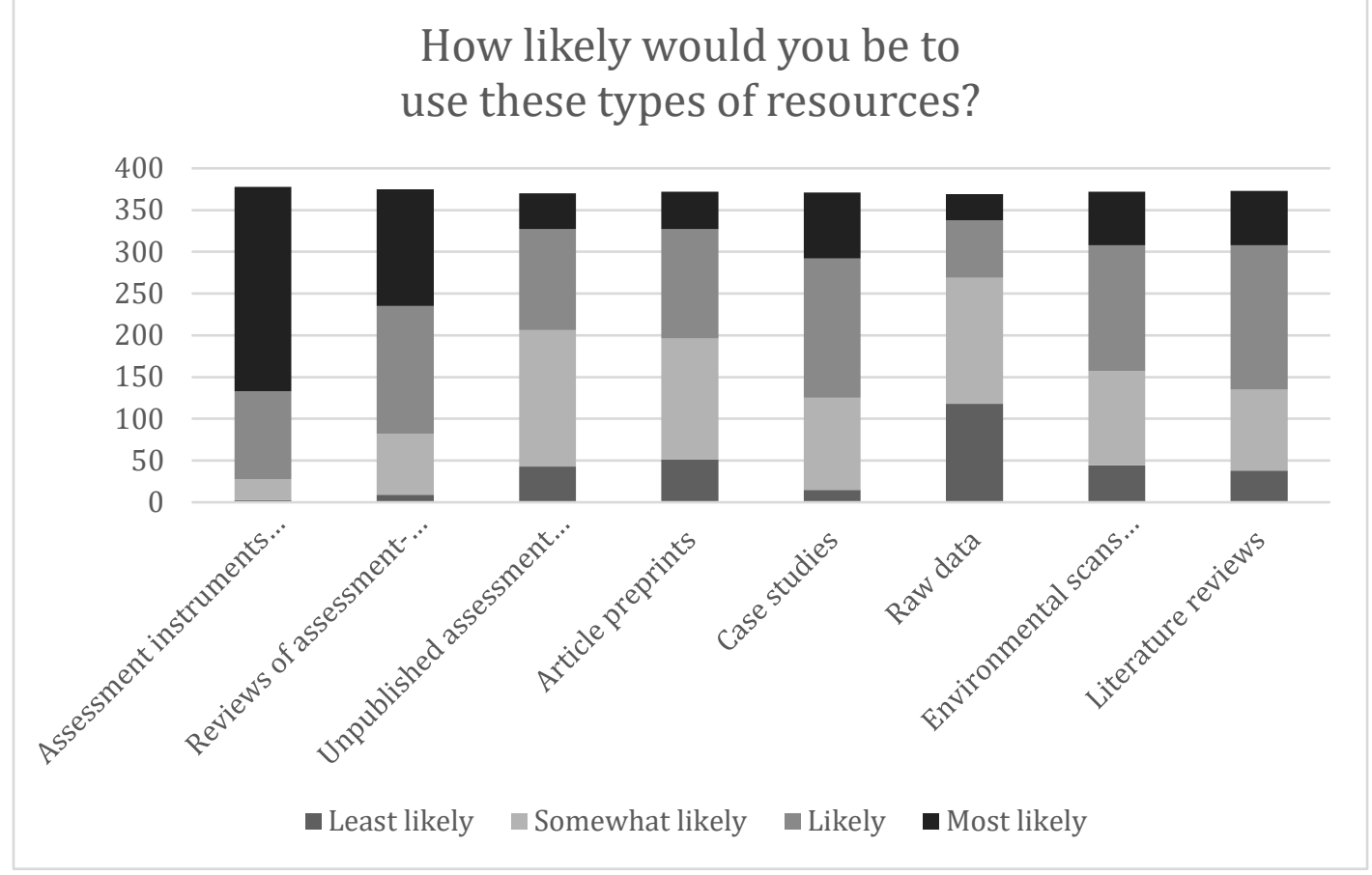


In open-ended comments, survey participants expressed a need for ease of access to the repository and resources that were freely available. They wanted robust searchability, good organization, and metadata. Some representative comments as to what factors would lead to likely use include:

- Easy to navigate and find resources

- Quality of resources

- Alignment of resources available to current assessment project need

- $\quad$ Ease of use

- Overall quality control

The survey included a set of parallel questions about factors contributing to a willingness to share resources. Again, the ease of deposit and accessibility were considered primary.

A repository is only as good as its comprehensiveness, and populating the repository with quality resources is critical. Users need to feel that their work is worth sharing and is of value to others. Concerns were expressed about the sharing of raw data because the context in which it is collected is essential to its understanding, or reanalysis. Privacy concerns, as well as permissions from administration and institutional review boards for sharing/publishing data were also considered barriers to depositing data sets.

And yet, we felt that the high response rate to the survey was an indicator that a tool for sharing assessment resources would have real potential benefit to the community. Many respondents used the survey comments section as an opportunity to express interest in the project.

While the results were somewhat helpful in prioritizing our requirements, they also established high expectations for the repository. Many questions, even contradictions, were raised from the start:

- How do we provide a seamless process for sharing resources, while also providing for quality materials?

- Would a peer review process be perceived as a disincentive to sharing assessment projects?

- In evaluating quality, how do we balance assessments that are designed for local decision-making with research findings of more generalizable use?

- What would that standard for "quality" be? Accurate metadata? Statistical validity?

- If the repository is meant for use by librarians from all types of libraries, can we develop standards that can be broadly applied?

- What incentives must be in place to encourage participation in the project?

\section{Managing the Pilot}

Balancing limited financial resources with continued support from the LLAMA Board, we requested funds to license Omeka.net ${ }^{3}$ for one year. This allowed us to get a better understanding of the time and expertise required for launching and maintaining an open-access site for deposit of resources related to library assessment. Omeka.net has limited customization options, but offers an array of tools for controlling metadata and includes plug-in applications to enhance functionality such as authority control and export of records. It allows for creation of "collections" for browsing and filtering of content. In addition to understanding the user interface for Omeka.net, the pilot helped us to learn more about its technical capacities and how various workflows and policies for submission would work with the platform.

Eighty respondents to the Needs Assessment Survey expressed interest in learning more about the repository. We reached out to these as potential volunteers for the project. Based on interest and experience, project coordinator Kirsten Kinsley organized the volunteers into three groups: Technology (led by Nancy Turner), Policies (led by Anne Moore), and Usability (led by Melissa Becher). Our total cohort of volunteers in Phase I of the pilot, conducted in winter/spring of 2017/18, was 15 people. 
Given the size of the group and the structure of three separate committees, documentation and clear communication about who was doing what was essential. There were times when questions that one group was wrestling with overlapped with the concerns and questions of the other groups. The project coordinator tried to be present in each of the groups' meetings to make sure that information was not accidently siloed into one group, but schedules sometimes got in the way of that approach. We improved our communication flow by implementing a more direct approach, with each project's meeting minutes shared across the leadership group via email.

Another challenge was populating the repository, even for the purposes of testing workflow and usability. Each group wrestled with minimizing user barriers to submission while also providing quality items and implementing sustainable administration of the repository. At this time, the repository contains 18 items of various types, organized into seven collections: Assessment Instruments, Datasets, Documentation, Journal Articles and Book Chapters, Reports, Web Resources, and Miscellaneous.

\section{Usability Testing}

The Library Assessment Repository Needs Survey found that participants considered ease of use to be a factor in whether they would use or contribute resources to a library assessment repository. Ease of use also figured prominently in the requirements proposed in Martha Kyrillidou's Library Assessment Repository Concept, Research, and Specifications document of 2016. In response, the User Experience group ${ }^{4}$ set a goal to find out whether Omeka.net and the item submission process fulfilled user expectations for usability. The group developed a usability test, conducted in May 2018, of the major tasks associated with use of the repository. Tasks included:

- submitting a document to the repository

- choosing collection, assessment method, and item type for the submission

- searching using the Omeka search bar

- browsing items using the Omeka Browse Items feature

- browsing collections using the Omeka Browse Collections feature

- downloading an item from the repository

The test included a post-task interview to reveal barriers or sticking points and to gauge how likely participants would be to use the repository and what other functionalities they might want. 
Figure 3: Home page of Library Assessment Repository Pilot Site

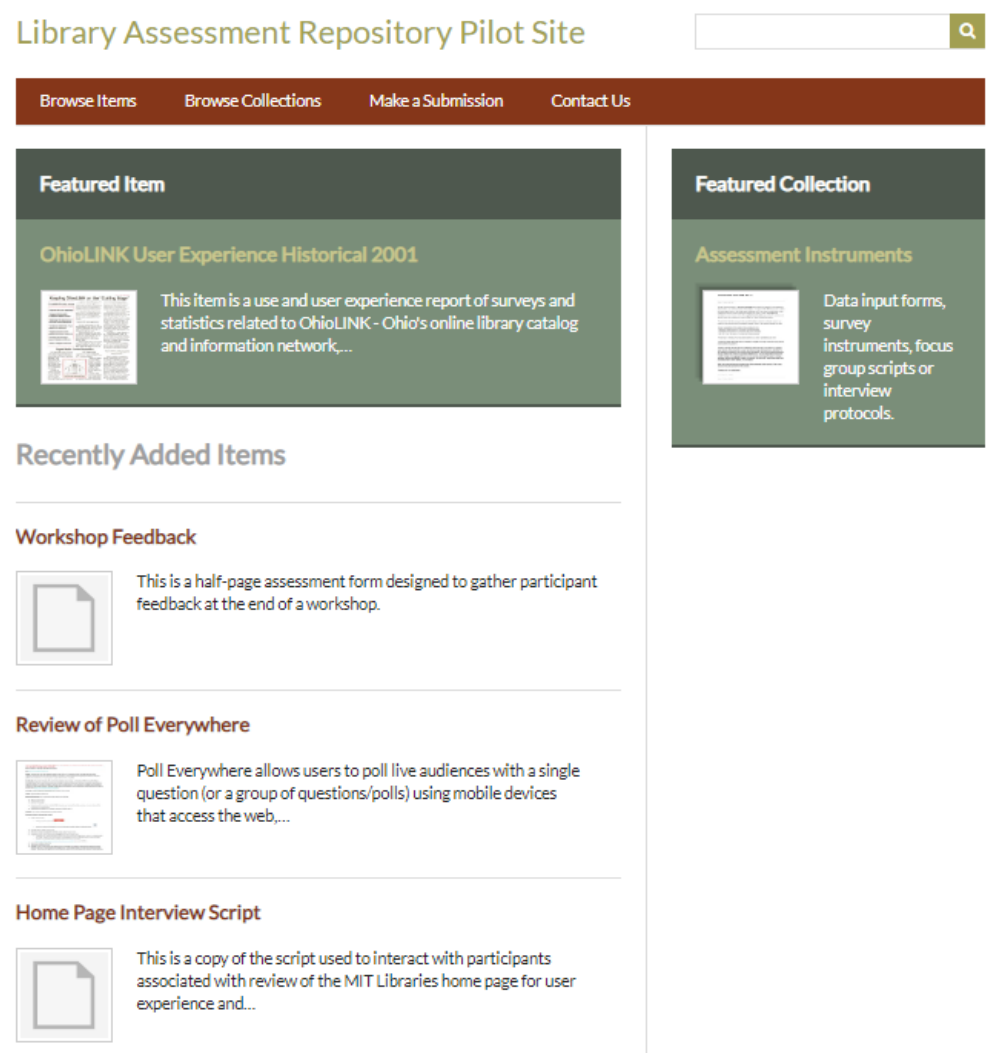

\section{Methodology}

Usability test best practices recommend testing five participants, as long as there are not distinct groups using a site in different ways. ${ }^{5}$ For this test, group members recruited seven librarians from various types of institutions representative of potential users of the repository. The breakdown of institution types was three academic, two public, one special, and one school. Two of the participants said that they had contributed to a repository before.

Some of the participants were located near members of the User Experience Group, but some were not. The group used a combination of in-person tests and remote tests using Zoom to reach all participants. A few of the tests were hybrids with a member of the group on-site with the participant and another member joining via Zoom. Tests went more smoothly when the participant shared their computer screen with the testers after navigating to the Omeka.net site. Activity on the shared screen was easily recorded using Zoom's recording feature for later analysis. Because of the minimal-risk nature of the tests, group members were able to streamline the informed consent process by taking consent verbally as part of the recorded session after distributing information about the project to the participant beforehand and providing an off-tape opportunity to ask questions.

IRB approval for the collaborative testing posed challenges. The initial proposal was approved by American University's IRB, but we wanted other members of the team to be able to run tests so that the work could divided more evenly. In order to take this approach, other group members had to get approval from their institutions' IRBs to participate as researchers under the oversight of American University. The group discovered that we had not left enough time for this part of the process and we were unable to get two IRB offices to fully understand the project and make deferral arrangements for their respective group members. With testing deadlines approaching, our solution for those who had not gotten a deferral from their 
institution's IRB was to work with a member who had. In these cases, the IRB-approved member took the lead on interacting with the participant.

\section{Results}

Participants rated the ease of each of the six usability tasks on a 5-point scale with 1 being difficult and 5 being easy. Figure 1 shows the ratings for all tasks. "Using the search bar" was the easiest task, followed by "Browsing collections," "Submitting an item," and "Choosing the collection, assessment method, and item type" on the submission form. "Browsing items" and "Downloading an item" were tasks rated difficult or somewhat difficult by one participant.

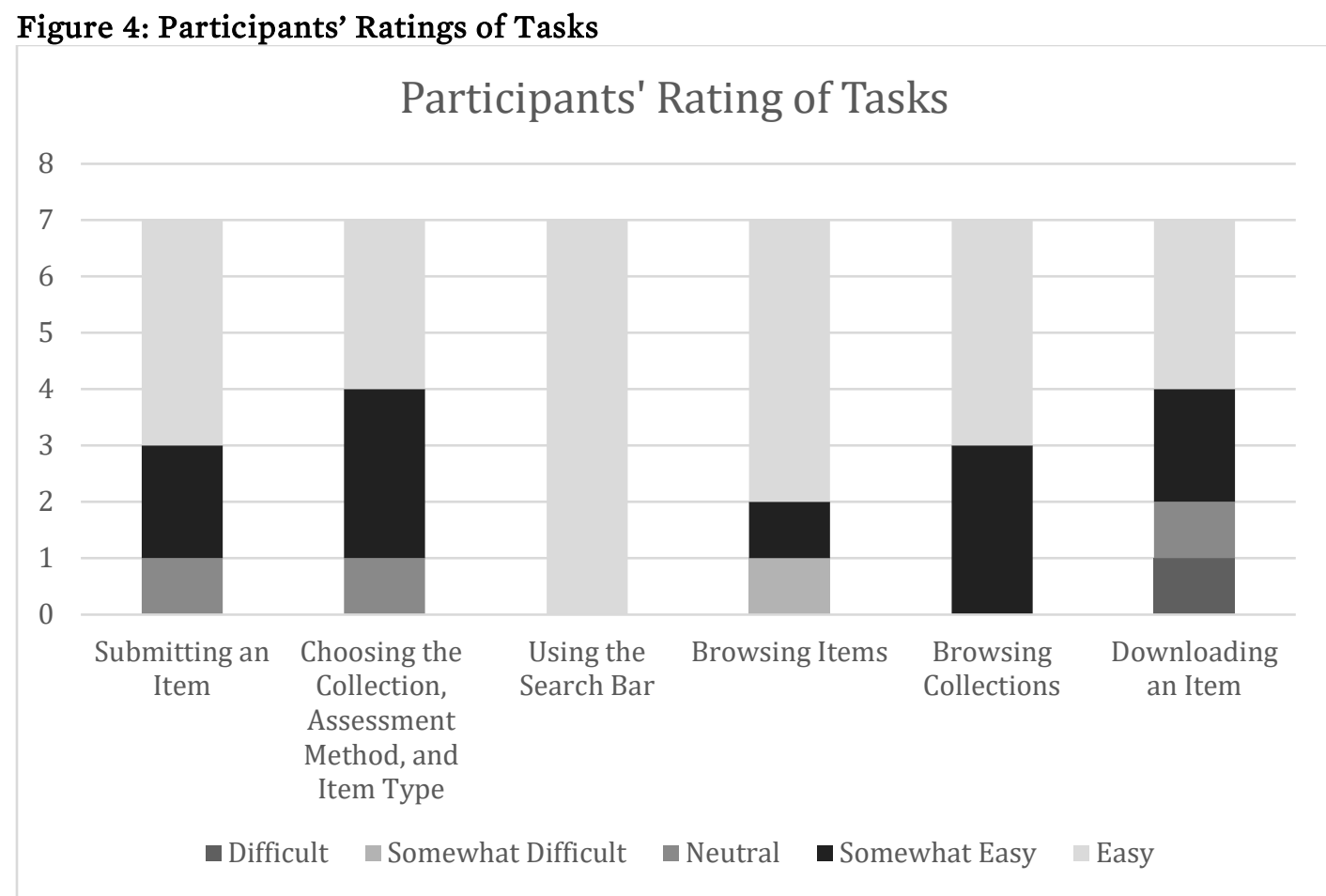

Participants commented that the Omeka search bar and browsing options worked well and thought the repository interface was clean and easy to read. Other comments noted that the collections were intuitive and that submitting and downloading documents was easy.

There were some sticking points in the submission process. Multiple participants had difficulty choosing Library of Congress subject terms and use rights for the test document they submitted. This may be in part because the test document, while relatively straightforward, was not one familiar to participants. However, the difficulties also point to the fact that there are complexities to submitting documents to a repository that may require previous external knowledge.

Another sticking point for multiple users was the Browse Collections feature. Omeka displays results of a Browse Collections search in an unexpected place-in the right hand column of the page rather than in the central area of the page. It also sorts in an unexpected way, putting "Miscellaneous" at the top instead of listing collections in alphabetical order. The group could change the sort order of collections to title but could not change the page template. Fortunately, the most prominent way to search-the Omeka search barwas rated "easy" by all participants.

Finally, one sticking point mentioned by a public librarian participant was the lack of a method to filter searches by type of institution. This participant said that the assessment public librarians typically do is less 
formal than academic studies and that public librarians find the rigor and statistical analysis of academic assessment off-putting. In order to encourage public librarian participation and use of the site, this participant felt there should be a way to separate out public library contributions to the repository. This functionality, unfortunately, is not available in Omeka.net. The closest users could come would be to search "public" in the Omeka search bar. The issue of possible public librarian frustration with academic assessment revealed by this test deserves further consideration by the leaders of the LAR project, which was envisioned as a resource "that will support the entire membership of American Library Association (ALA) across all library types and functions and also non-ALA members interested in library assessment." ${ }^{6}$ It may be an argument for an overlaying website that all types of librarians would find welcoming.

Other functionality desired by individual participants that was not technically possible in the Omeka.net platform included the ability to submit files by dragging and dropping them, the ability to change the number of search results displayed, a download button, and the ability to link to multiple document records, particularly if they related to the same project. These requests illustrate the challenges of using a platform intended for the storage and display of visual materials from a single entity to store text documents from a large number of separate entities. The larger scale of the LAR with the resulting greater demand for uploading, downloading, and linking related documents will need to be weighed against Omeka.net's easy navigation and searching when coming to an ultimate decision about the repository platform.

\section{Lessons Learned}

From our original needs survey leading to Phase I of the pilot project and testing the user experience for the platform, we have been learning as we go. Each of these assessments has provided us lessons:

The needs assessment survey pointed to the community's desire for a tool for sharing resources related to library assessment. The survey results helped us to advocate for support from the LLAMA Board to host a pilot site. In retrospect, asking respondents to rank their choices or choose the top three desired types of materials would have provided more actionable information towards prioritizing our repository requirements and its scope.

Usability testing contributed to the success of the Library Assessment Repository pilot in several ways. The group learned much about remote testing with Zoom and Institutional Review Board (IRB) processes that will be useful for future testing of the repository and/or a related website. Test results revealed that the Omeka.net platform meets requirements for ease of use as stated in the initial repository concept and emphasized by participants in the needs assessment survey. Finally, the interview portion of the test gathered important qualitative data regarding audience and platform that will inform future decisionmaking regarding the repository.

\section{Pilot Project Process}

While the survey and the usability testing of the site provided examples, and findings of assessment practice, our project process itself continues to be a learning experience to ensure that the repository project incorporates a process of continuous improvement and overall sustainability.

The primary goals of the pilot were described in the first volunteer meeting in January 2018. Prior to the meeting, a LAR Basics document was created to introduce volunteers to the project goals, audience, scope, and use of Omeka.net as a proof of concept. For this orientation meeting, the projected outcome of the project was clearly laid out at the beginning: "Decide whether or not to recommend to LLAMA (our primary stakeholder) whether we should use this version of Omeka (Omeka.net) for a LAR." The choice was made to focus on the goals of the Omeka.net pilot rather than get bogged down in the minutiae of project history.

For the complex project, it made sense to divide the tasks as we did, and the project coordination was handled with diligence. The challenge was each group saw the project from their own perspectives. Additionally, working as virtual groups can exacerbate barriers in communication towards establishing 
shared purpose and addressing questions together. In Phase II of the project, we have formed a single team that works together, although each volunteer brings particular interests.

We learned that establishing a cohesive team is also difficult when membership changes each year. In the future, we will recommend a longer term commitment from our volunteers. As people came and went, it might have been helpful to reiterate the goals and projected outcome of the pilot.

Testing software based on a grassroots, volunteer-based approach is not easy, but it provided librarians from varying backgrounds an opportunity to come together and share their expertise. Our challenge was to balance valuing fresh ideas from a developing team with not reinventing the wheel or rehashing past decisions. Additionally, we wanted to provide opportunities for new librarians to network and publish/present about the project.

\section{Next Steps}

The original vision for the repository was compelling, but challenged our decision-making even within the context of exploring Omeka.net. In retrospect, it is difficult to separate out policy, procedures, or usability from technical functionality.

As we move into the next phase of the project, we must address and resolve the following questions:

- How best do we prioritize the desired purposes for the repository?

- Resource Sharing

- Preservation

- Resource for comparative research

- Networking

- Community Building

- Should we focus on one type of resource only and if we focus our efforts too early in the process, would we limit our understanding of the platforms' capacity?

- Should we establish and commit to these requirements and wait until an appropriate platform and resources are available to meet the need? 

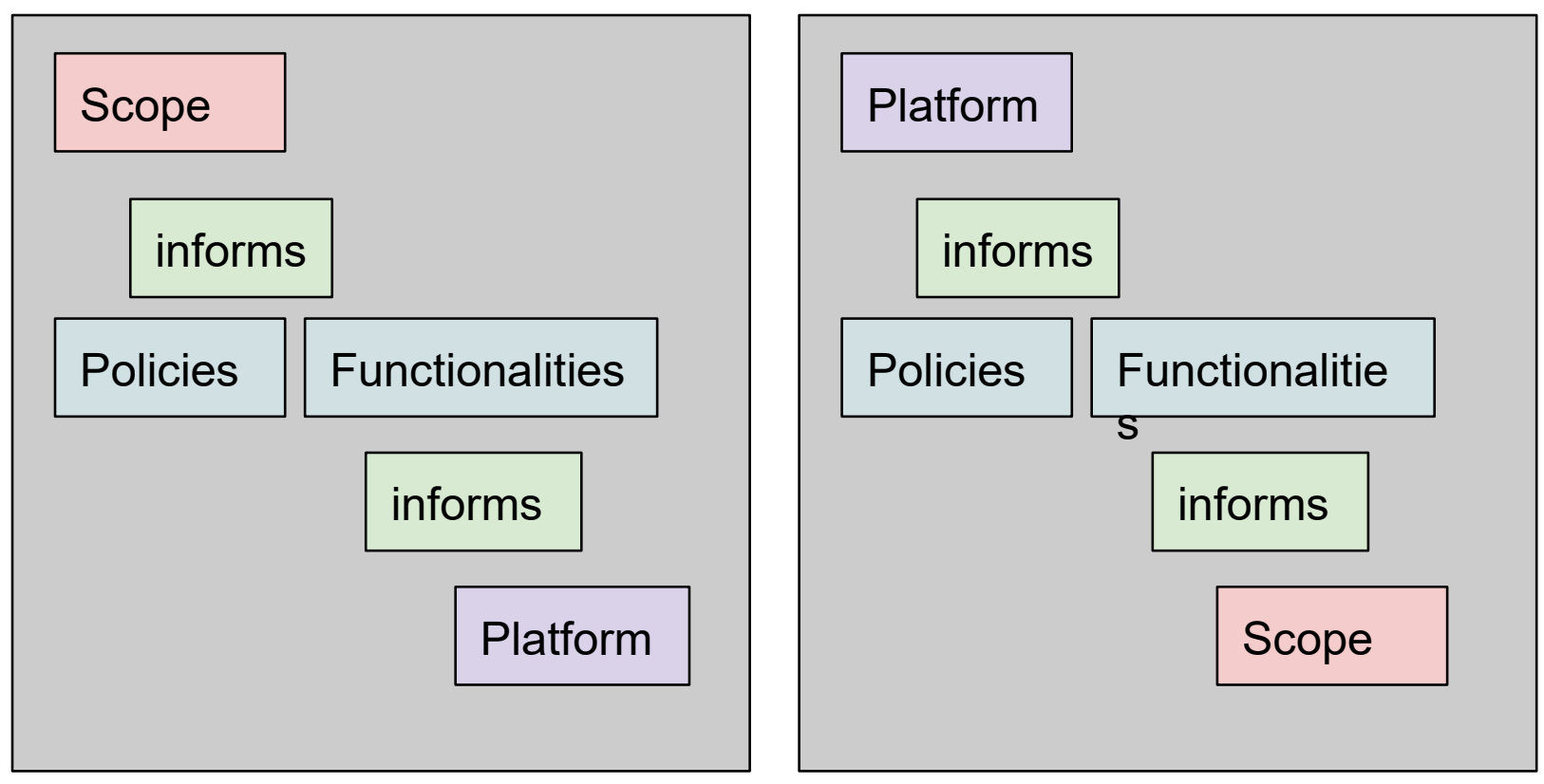

\section{Financial Constraints}

\section{Technical Expertise}

\section{Volunteer Time}

\begin{tabular}{|c|}
\hline Marketing \\
\hline \hline Sustainability \\
\hline
\end{tabular}

Adding on to this complexity, we are presented with limits on financial resources, time, and expertise, particularly technical expertise. We layer onto this the substantial effort of volunteer recruitment and building and marketing a sustainable space. On top of that, issues of preservation and building community need to be addressed.

As we move into Phase II of the pilot, we are in a position to tweak the process of developing and managing the project. The platform, Omeka.net, has many advantages in terms of ease of use, cost, and administration. But it is designed for digital projects much smaller than ours, and with fewer potential contributors. While it continues to be frustrating to work within the technical limitations of Omeka.net, establishing an actual site has allowed us to explore, on a very small scale, issues of access, discovery, metadata standards, policies, and workflow. If the project were to grow, we have identified some key areas that would need to be addressed.

In Phase II, we will continue to test alternative workflows for the repository. We now have a product and knowledge to share with the assessment community and look forward to continuing efforts to recruit resources and solicit ideas for a path forward. The Library Assessment Conference (December 2018) provided a perfect venue with which to do this.

As an iterative process that incorporates assessment at many levels, the Library Assessment Repository Pilot project is illustrative. It provides a story of persistence and flexibility, as our expectations for what we build 
with the resources available to us are limited. Finally, it is a story of collaboration and teamwork, of many, many volunteers who were willing to share the work of having the goal realized.

-Copyright 2019 Nancy B. Turner, Kirsten Kinsley, and Melissa Becher

Nancy B. Turner, Associate Director for Organizational Research \& Strategy Alignment, Temple University Libraries

Kirsten Kinsley, Assessment Librarian, Florida State University

Melissa Becher, Associate Director, Research Teaching, and Learning, American University Library

\section{Endnotes}

1. Data Collection for Library Managers, Measurement and Evaluation Section and Planning \& Evaluation of Library Services, Library Organization and Management Section.

2. From Assessment Repository Consultant RFP Year 1 at https://drive.google.com/open?id=0B69TM0_YtEHoVVhiNFQxd1lLbFA0ZEpyNnBfVW1CaGhsNFB3.

3. It should be noted that Omeka.net and Omeka are two separate products. Omeka.net, as an inexpensive "hosted" option for the repository, has fewer customization options, but allows us to design and explore various workflows.

4. Members of the group were Melissa Becher (Associate Director of Research, Teaching, and Learning, American U), Team Lead; Tricia Boucher (User Experience Librarian/Psychology Librarian, Texas State U); Kristina Clement (Graduate Student, University of Tennessee Knoxville); Brianne Dosch (Graduate Student, University of Tennessee, Knoxville); Laura Spears (Assessment Librarian, University of Florida); and Krystal Wyatt-Baxter (Head of Assessment, University of Texas at Austin).

5. Nielsen, Jakob. “Why You Only Need to Test with 5 Users," Nielsen Norman Group, 2000, https://www.nngroup.com/articles/why-you-only-need-to-test-with-5-users/.

6. Martha Kyrillidou, Library Assessment Repository Concept, Research, and Specifications, Quality Metrics, LLC, 2016, https://docs.google.com/document/d/12T9WzcrmylzPZTP2MxmTpA Bec0d82Qq6cKsCuhAvwaQ/edit. 


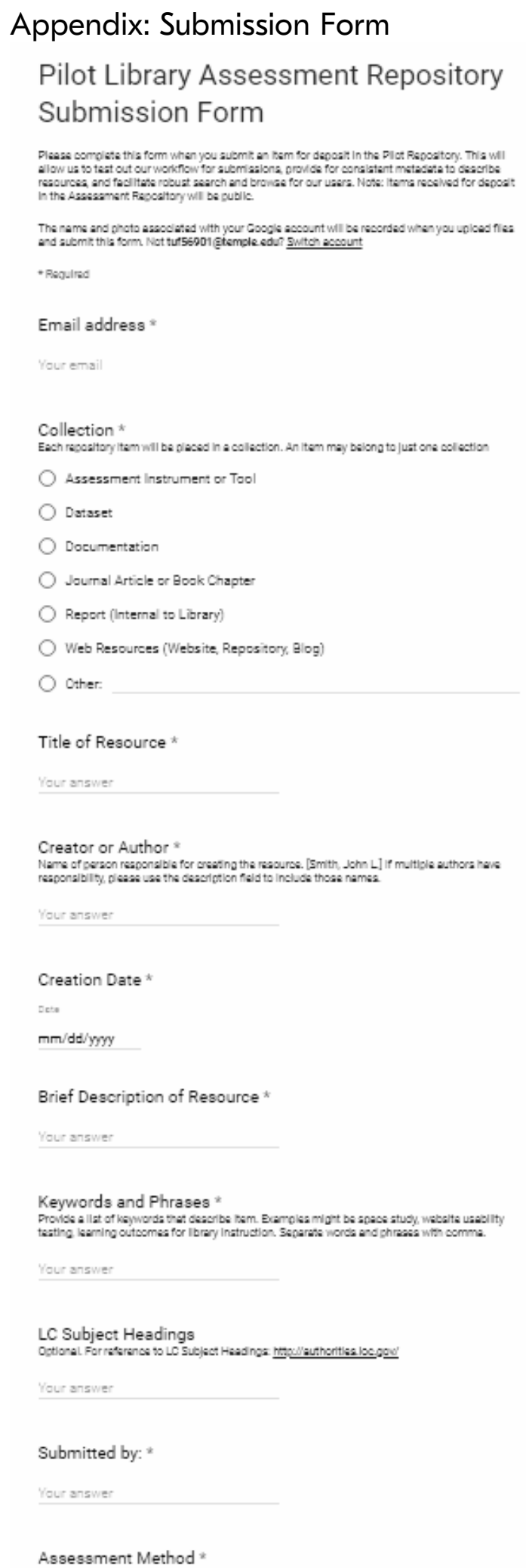

